Published in final edited form as:

Int Rev Immunol. 2013 February ; 32(1): 4-18. doi:10.3109/08830185.2012.749400.

\title{
Host Defense at the Ocular Surface
}

\author{
Eric Pearlman ${ }^{1}$, Yan Sun ${ }^{1}$, Sanhita Roy ${ }^{1}$, Mausita Karmakar ${ }^{1}$, Amy G. Hise ${ }^{2}$, Loretta \\ Szczotka-Flynn ${ }^{1}$, Mahmoud Ghannoum ${ }^{3}$, Holly R. Chinnery ${ }^{5}$, Paul G. McMenamin ${ }^{6}$, and \\ Arne Rietsch ${ }^{4}$ \\ ${ }^{1}$ Department of Ophthalmology and Visual Sciences, Case Western Reserve University, \\ Cleveland, $\mathrm{OH}, \mathrm{USA}$ \\ ${ }^{2}$ Center for Global Health and Diseases, Case Western Reserve University, Cleveland, OH, USA \\ ${ }^{3}$ Department of Dermatology Case Western Reserve University, Cleveland, OH, USA \\ ${ }^{4}$ Department of Molecular Biology and Microbiology, Case Western Reserve University, \\ Cleveland, OH, USA \\ ${ }^{5}$ School of Medicine (Optometry), Deakin University, Victoria, Australia \\ ${ }^{6}$ Department of Anatomy \& Developmental Biology, Monash University, Victoria, Australia
}

\section{Abstract}

Microbial infections of the cornea frequently cause painful, blinding and debilitating disease that is often diffcult to treat and may require corneal transplantation. In addition, sterile corneal infiltrates that are associated with contact lens wear cause pain, visual impairment and photophobia. In this article, we review the role of Toll-Like Receptors (TLR) in bacterial keratitis and sterile corneal infiltrates, and describe the role of MD-2 regulation in LPS responsiveness by corneal epithelial cells. We conclude that both live bacteria and bacterial products activate TollLike Receptors in the cornea, which leads to chemokine production and neutrophil recruitment to the corneal stroma. While neutrophils are essential for bacterial killing, they also cause tissue damage that results in loss of corneal clarity. These disparate outcomes, therefore, represent a spectrum of disease severity based on this pathway, and further indicate that targeting the TLR pathway is a feasible approach to treating inflammation caused by live bacteria and microbial products. Further, as the $P$. aeruginosa type III secretion system (T3SS) also plays a critical role in disease pathogenesis by inducing neutrophil apoptosis and facilitating bacterial growth in the cornea, T3SS exotoxins are additional targets for therapy for $P$. aeruginosa keratitis.

\section{Keywords}

bacteria; cornea; epithelial cells; Pseudomonas aeruginosa; Toll-like receptors

\section{INTRODUCTION}

Corneal ulcers caused by microbial infections are a major cause of preventable blindness worldwide as cited by the World Health Organization and Vision 2020 [1]. The most

Copyright (C) Informa Healthcare USA, Inc.

Address correspondence to Eric Pearlman, Ph.D., Department of Ophthalmology and Visual Sciences, Case Western Reserve University, 10900 Euclid Ave, Cleveland, OH 44106 USA. Eric.Pearlman@ case.edu.

Declaration of Interest None of the authors have any financial interest in the work presented in this review. The authors alone are responsible for the content and writing of the paper. 
common bacterial pathogens worldwide are Pseudomonas aeruginosa, Staphylococcus aureus and Streptococcus pneumoniae. Fungal pathogens include Fusarium, Aspergillus, and Candida species, and parasitic causes include Acanthamoeba and the Onchocerca volvulus worm that causes river blindness. In the latter case, endosymbiotic Wolbachia bacteria play a critical role in corneal inflammation associated with this disease by bacterial lipopeptides that activate TLR2/TLR6/MyD88 signaling in the cornea [2-4]. Herpes simplex virus (HSV), which is a major cause of infectious keratitis in the USA, is maintained in the latent stage in trigeminal ganglia by CD8 cells [5]. However, following primary infection and resurgence, induces corneal disease associated with pronounced neovascularization, and is regulated by CD4 cells [6, 7]. Chlamydia trachomatis bacteria that cause trachoma are primarily located in epithelial cells of the palpebral conjunctiva. However, chronic conjunctival inflammation can cause scarring and subsequent inward turned eyelashes which rub on the cornea, leading to secondary corneal disease. Fungal keratitis is associated with increased innate immunity mediated by the c-type lectin Dectin-1, which recognizes fungal cell wall $\beta$-glucan and induces chemokine production and neutrophil recruitment to the cornea $[8,9]$. Acanthamoeba keratitis is less well understood, although there is an important role for Acanthamoeba lectins, proteases and possibly intracellular bacteria [10,11]. As there are recent reviews on river blindness [4], trachoma [12], fungal keratitis [13] Acanthamoeba keratitis $[10,11]$ and HSV keratitis, the current review will focus on the mechanisms of innate immunity that underlie corneal inflammation and bacterial keratitis, primarily Pseudomonas aeruginosa keratitis. This review will also examine how $P$. aeruginosa virulence factors impair the host response and mediate bacterial replication in the cornea. Further, although $\mathrm{CD}^{+}$cells regulate neutrophil recruitment and the outcome of HSV keratitis and later stages of $P$. aeruginosa keratitis, the role of adaptive immunity has been reviewed elsewhere [14-16]; therefore, the current review will focus on innate immune responses associated with acute stage corneal disease.

\section{Innate Immunity at the Corneal Surface}

The cornea is protected by the tear film, which contains antimicrobial peptides such as $\beta$ defensins and calprotectin (S100A8/A9) [17], lysozyme, lipocalin, and lactoferrin that bind and restrict the availability of free iron or which bind microbial siderophores, and are present in higher concentrations during inflammation [18, 19]. In addition, the mucin layer comprising $\mathrm{MUC}_{1}, \mathrm{MUC}_{4}$, and $\mathrm{MUC}_{16}$ forms a dense glycocalyx on the apical surface of the corneal epithelium and provides a physical barrier that restricts bacterial adherence [20]. If the epithelium is breached, corneal epithelial cells can respond by also producing antimicrobial peptides, including $\beta$-defensins and cathelicidin (LL-37) [21]. In vivo studies showed that $\beta$-defensins 2 and 3 have an important role in protection against $P$. aeruginosa $[22,23]$. Further, a recent study by Tam and Fleiszig identified a novel class of antimicrobial peptides are constitutively produced from cytokeratin-6A in corneal epithelial cells [24]. These keratin-derived antimicrobial peptides (KDAMPs) have a distinct secondary structure and are distinct from $\beta$-defensins in being stable in physiological saline, and having broad anti-microbial activity [24].

\section{Toll-Like Receptors (TLR)}

The TLR family is a class of single membrane-spanning receptors that recognize structurally conserved molecules derived from microbes (reviewed in [25]). Thirteen TLRs have been identified in humans, which respond to lipids, proteins or nucleic acids. All TLRs (with the exception of TLR3) and IL-1R1 signal through the TIR domain to recruit the MyD88 common adaptor molecule, leading to NF-kB translocation to the nucleus [26]. In addition to the MyD88 pathway, TLR3 and TLR4 activate the TRIF pathway, which induces IRF3 transcription and production of type I interferons that mediate antiviral responses [26]. A recent study showed that CD14 also mediates TLR4 endocytosis by activating the ITAM/ 
Syk/PLC $\gamma 2$ pathway, and that once in the endosome, TLR4 recruits the TRAM and TRIF adaptor molecules to activate IRF3 [27].

TLR2 and TLR4 recognize lipids with TLR2 forming a heterodimer with TLR1 or TLR6 and responding to di- and tri-acylated lipopeptides, and TLR4 responding to the lipid A moeity of lipopolysaccharide (LPS) [26]. TLR5 and TLR11 recognize proteins, and are activated by bacterial flagellin (TLR5) or uropathogenic E.coli or Toxoplasma gondii profilin [28, 29]. TLR4 activation involves accessory molecules, including lipopolysaccharide (LPS) binding protein and CD14, which combine to extract single endotoxin molecules from the outer membrane and form monomeric endotoxin. The CD14 / LPS complexes are then transferred from CD14 to MD-2, which couples endotoxin recognition to TLR4 activation to form the LPS receptor [30-32]. The crystal structure of the TLR4/MD-2 complex shows that when five of the six acyl chains of lipid A bind MD-2 and one chain binds to TLR4, it undergoes a structural change that facilitates dimerization and cell activation [33]. The combined activity of TLR4 accessory molecules facilitates recognition of LPS at picomolar concentrations [34].

\section{Resident Myeloid Cells and the Role of TLRs in the Cornea}

The mammalian cornea was for many years thought to be devoid of myeloid cells and therefore immune privileged until a series of elegant studies using whole mount corneas and confocal microscopy demonstrated that healthy corneal stroma and epithelium contain heterogeneous populations of macrophages and dendritic cells [35-39]. Examples are shown in Figure 1 in which resident bone marrow derived cells expressing the fractalkine receptor $\mathrm{CX}_{3} \mathrm{CR} 1$ on a GFP reporter $\left(\mathrm{CX}_{3} \mathrm{CR} 1^{\text {gfp+ }}\right.$ mice$)$ are detected in normal corneas. These cells, which can be mostly replenished within eight weeks after radiation ablation [39] mediate the initial response in the cornea to LPS and $P$. aeruginosa [40, 41]. This series of studies also demonstrated the first in vivo identification of membrane nanotubes, which are thought to facilitate cell-cell communication in the cornea [36].

P. aeruginosa activation of macrophages rapidly stimulates MyD88, TRIF, and TIRAP dependent production of pro-inflammatory and chemotactic cytokines in vitro and in vivo, and mediate neutrophil recruitment to the corneal stroma and bacterial killing [40]. Huang and Hazlett also reported a role for TLR4 and for macrophages in regulating $P$. aeruginosa keratitis, although they implicated a role for TLR4 in expression of antimicrobial peptides rather than neutrophil infiltration [41, 42]. It is likely that neutrophils and epithelial cell derived antimicrobial peptides have a significant role in bacterial killing.

These reports are consistent with the sequence of events illustrated in Figure 2 in which $P$. aeruginosa LPS and flagellin initiate the host response by activating TLR4/MD-2 and TLR5 on resident macrophages in the corneal stroma. Not shown is recruitment of adaptor molecules MyD88 to TLR4 and TLR5, and recruitment of TIRAP and TRIF to TLR4, all of which lead to NF- $\kappa$ B translocation to the nucleus, and expression of pro-inflammatory and chemotactic cytokines. These include CXCL1/KC, which recruits neutrophils from limbal capillaries to the corneal stroma, and IL- $1 a$ and IL- $1 \beta$, which then activate the IL-1R1 / MyD88 pathway in macrophages and resident corneal epithelial cells and keratocytes [40]. Together, these cytokines mediate in neutrophil recruitment from limbal vessels to the site of infection in the corneal stroma, where they have an essential role in bacterial killing. Although the mechanism of neutrophil killing in bacterial keratitis has yet to be determined, NADPH oxidase generation of reactive oxygen species (ROS) has a critical role in regulating hyphal growth during fungal keratitis [43]. However, neutrophil production of ROS and MMPs including collagenases also disrupts the extracellular matrix, preventing microbial dissemination [44]. In the cornea, these mediators also cause disruption of the normal collagen matrix, resulting in loss of corneal clarity and impaired vision. 


\section{TLR Expression and LPS Responsiveness in Human Corneal Epithelial (HCE) Cells}

Corneal epithelial cells form tight junctions that comprise the outer, protective cell layer of the cornea. With few exceptions such as extended incubation with contact lenses containing a large number of $P$. aeruginosa bacteria [45], microbial invasion or stromal inflammation requires disruption of the epithelial barrier. However, once this occurs, resident cells in the cornea respond to LPS and TLR2, TLR3, TLR5, and TLR9 ligands by producing chemokines that mediate recruitment of bone marrow derived cells. [46-50]. A recent study by Chinnery et al. showed that activation of TLR9 in the cornea also induces retinal inflammation [51], although the mechanism has yet to be determined.

In vitro, human corneal epithelial cells respond to TLR2, TLR3, and TLR5 ligands, but are unresponsive to LPS [52-54]. Although there are reports that LPS unresponsiveness is due to the absence of TLR4 on the cell surface [47, 53], others showed that MD-2 is not expressed and that LPS responsiveness is conferred by exogenous MD-2 or transfection with an MD-2 expressing plasmid [52, 54, 55]. In support of the latter findings, Roy and coworkers demonstrated by flow cytometry that TLR4 is constitutively expressed on the surface of human corneal epithelial cells, whereas MD-2 is not detected at the RNA or protein level [56]. However, incubation with IFN- $\gamma$, which activates the Jak2/STAT1 pathway and $p$-STAT1 binding to IFN Gamma Activating Sites (GAS) on the MD-2 promoter, results in MD-2 gene and surface expression, and LPS responsiveness [56]. As IFN- $\gamma$ is produced by infiltrating natural killer cells during $P$. aeruginosa corneal infection $[56,57]$, it is likely that LPS responsiveness by corneal epithelial cells is secondary to that of myeloid cells, but further contributes to the inflammatory response during active bacterial infection by producing pro-inflammatory and chemotactic cytokines (Figure 3 ). Although not shown for LPS, HCE cells produce antimicrobial peptides in response to TLR2, TLR3, and TLR5 ligands, including $\beta$-defensins and cathelicidin $[47,58,59]$.

\section{IL-1 $\beta$ Processing in $P$. aeruginosa Keratitis}

IL- $1 \beta$ has an important role in the host response to $P$. aeruginosa corneal infection, as mice depleted of or deficient in this cytokine or its receptor are unable to clear the bacteria [60, 61]. Production of mature, functional IL- $1 \beta$ is a two-step process requiring an initial signal to induce transcription of the $31 \mathrm{kDa}$ pro-form, and a second signal for post-translational cleavage to the $17 \mathrm{kDa}$ mature form $[62,63]$.

Caspase-1 is activated by the assembly of a multiprotein complex containing one or more Nod-like receptors (NLRs), called "inflammasomes." The NLRs consist of a C-terminal LRR (Leucine-rich repeats) domain, a central nucleotide-binding (NACHT) domain, and a variable $N$-terminal domain, which can be a CARD, Pyrin or BIR domain [62, 63]. The NLRC4 inflammasome (also termed IPAF) is expressed in macrophages and is activated by flagellin or Type III secretion proteins (see below), leading to caspase-1 recruitment and IL-1 $\beta$ cleavage [64-66].

Although most of these studies were based on macrophage cultures, an in vivo role for NLRC4 has been implicated in murine models of $P$. aeruginosa lung infection and Candida oral infection [67, 68]. Macrophages are recruited to the corneal stroma, neutrophils are the earliest and most numerous cells infiltrating the stroma following infection; however, Karmakar et al. examined the role of neutrophils at early time points following $P$. aeruginosa corneal infection, and demonstrated that neutrophils were the primary source of IL-1 $\beta$, and that IL- $1 \beta$ processing in the cornea was independent of caspase-1 and NLRC4 [61]. Instead, the pro-form of IL- $1 \beta$ was cleaved by neutrophil elastase. Caspase- 1 and elastase cleave the $31 \mathrm{kD}$ pro-IL- $1 \beta$ at different sites, resulting in different sized cleavage products; however, both enzymes generate the $17-18 \mathrm{kD}$ bioactive form of IL-1 $\beta[69,70]$. 
Although there was no apparent role for NLRC4 or caspase-1 during infection, highly purified populations of NLRC $4^{-/-}$and caspase- $1^{-/-}$neutrophils had impaired IL- $1 \beta$ processing, indicating that neutrophils also express inflammasome components. This observation is consistent with a recent study showing RNA expression of inflammasomes and caspase-1 in neutrophils that can mediate IL- $1 \beta$ processing in vitro [71], indicating that neutrophil inflammasomes may also have a role in microbial infections.

Hazlett et al. reported that caspase- 1 contributes to $P$. aeruginosa keratitis at later time points when macrophages are more numerous [72,73]; however, given the ubiquitous presence of neutrophils in acute bacterial infections, it is likely that neutrophil mediated IL- $1 \beta$ processing has a broad role in early stage infection, with macrophage and possibly neutrophil inflammasome activity contributing at a later stage (Figure 4).

\section{TLR Suppressor Responses in P. aeruginosa Keratitis}

As TLR activation needs to be regulated, suppressing the host response to $P$. aeruginosa involves several pathways, including members of the TLR family, neuropeptides that downregulate TLR activity, and pre-treatment with flagellin.

Single Ig interleukin-1R-related molecule (SIGIRR) is a member of the TLR-IL-1R superfamily that negatively regulates TLR and IL-1R responses [74]. Huang and Hazlett demonstrated that blockade of SIGIRR results in enhanced $P$. aeruginosa keratitis [75]. These investigators reported that the ST-2 receptor is also expressed and has an inhibitory role during infection [76].

Neuropeptides also have immunoregulatory activity, and as the cornea is heavily innervated, Hazlett and co-workers examined their role in $P$. aeruginosa keratitis and reported that vasoactive intestinal peptide (VIP) inhibits pro-inflammatory cytokine production and enhances expression of antimicrobial peptides by regulating growth factors [77, 78]. Conversely, substance $\mathrm{P}$ induces a pro-inflammatory response in this model, at least in part by inhibiting neutrophil apoptosis $[79,80]$.

Although somewhat counter-intuitive, pre-exposure to flagellin has a protective effect against radiation-induced injury (?) and bacterial infections [81, 82] Kumar and $\mathrm{Yu}$ demonstrated that topical flagellin given prior to $P$. aeruginosa corneal infection results in enhanced bacterial clearance and less corneal disease by inducing expression of cathelicidin related antimicrobial peptide (CRAMP) [83, 84]. The suppressive activity of flagellin was not unique to the cornea, as prior instillation of flagellin also protected mice from pulmonary infection with $P$. aeruginosa by a similar mechanism [85].

\section{P. aeruginosa Type III Secretion System}

Although bacterial infections induce a rapid host response, most organisms express virulence factors that counter this response and facilitate bacterial survival. The Type III Secretion System (T3SS) used by Gram-negative bacteria is a complex, needle-like organelle designed to inject bacterial effector proteins directly into host cells. It is comprised of a basal body, which spans the bacterial cell envelope, and is connected to a needle that protrudes from the surface of the bacterium. Injection of effector proteins into targeted hostcells is contact dependent and requires the action of the two translocator-proteins, PopB and PopD in $P$. aeruginosa. These translocator proteins form a pore in the host-cell membrane through which the effector proteins are injected $[86,87]$. The effector proteins can prevent wound healing and phagocytosis, and promote dissemination of the bacteria [87].

As shown in Figure 5 and reviewed in [86, 87], the $P$. aeruginosa T3SS can deliver up to four effector proteins (exoenzymes): ExoS, ExoT, ExoU, and ExoY. ExoU has potent 
phospholipase activity and causes rapid lysis of host cells [88], whereas ExoY is an adenylate cyclase [87]. ExoS and ExoT are closely related and have GTPase activating protein (GAP) and ADP ribosyltransferase (ADPRT) activities [89], The Rho-GAP domains of these two proteins which target a similar subset of GTPases, including Rho, Rac1, and CDC42 [90, 91]. Together Rho-GAP and ADPRT activities alter host cell cytoskeletal function, resulting in impaired cell migration and adhesion, in addition to blocking phagocytosis, disrupting epithelial cell barriers and preventing wound healing [87, 89, 92].

Almost every strain of $P$. aeruginosa contains ExoT and about $86 \%$ of strains harbor the gene for ExoY; however, for reasons that are not yet clear, most $P$. aeruginosa isolates express either ExoS or ExoU, but not both effectors [93]. ExoS- and ExoU-expressing isolates are recovered from infected corneas at similar frequencies [94]. Despite the difference in T3SS production, the dependence on TLR4 and TLR5 pathways in corneal infection are the same for both strains [93].

The importance of type III secretion in corneal infections was first demonstrated for the ExoU-expressing strain PA103 [95]. More recently, Sun et al. examined strains PAO1 and PAK, which express ExoS, ExoT, and ExoY, but not ExoU, and demonstrated using a series of mutants that type III secretion is required for corneal disease elicited by these two strains of $P$. aeruginosa also [96]. This group also showed that the ADP ribosyltransferase rather than the Rho-GAP activities of ExoS and ExoT mediate bacterial survival in the cornea by promoting neutrophil apoptosis and bacterial survival in neutrophils. Consistent with these findings, Fleiszig and co-workers also showed a role for the ADPR activity of ExoS in sequestering $P$. aeruginosa in membrane blebs of epithelial cells $[97,98]$.

\section{Biofilm Formation-Increased Risk of Bacterial Keratitis and Corneal Inflammation}

The ability of bacteria and fungi to adhere and form biofilm on biological and synthetic substances is an important virulence attribute, facilitating bacterial communication and nutrient exchange, and conferring protection from cellular infiltration and resistance to antibiotics $[99,100]$. Antibiotic resistance is partly due to limited physical access to bacteria that are not on the biofilm surface, but also to physiological heterogeneity with bacteria localized in microniches within the biofilm [99]. Szczotka-Flynn and co-workers showed that $P$. aeruginosa, Serratia marcescens and Staphylococcus aureus can form a biofilm on silicone hydrogel contact lenses, and that biofilm is more resistant to antibiotics than planktonic bacteria, thereby increasing the risk of corneal inflammation and infection [102, 104].

\section{Serratia marcescens and Sterile Corneal Inflammation}

In addition to LPS, lipopeptide ligands for TLR2, TLR5 stimulation by flagellin and nucleic acid stimulation of TLR3 and TLR9 can also induce corneal inflammation [48, 103]; TLR3 can also down-regulate MyD88 activity in corneal epithelial cells [48].

In addition to active corneal infection (keratitis), corneal inflammation occurs even in the absence of culturable bacteria and can result in significant discomfort and occasionally visual impairment, often as a consequence of contact lens wear. Although less severe than active keratitis, there are an estimated 134 million contact lens wearers worldwide, making sterile corneal inflammation and important clinical and economic concern. Organisms such as Serratia marcescens and coagulase negative Staphylococcal species are routinely isolated from lenses and lens cases [101, 103]. These bacterial products in addition to uncharacterized bacteria on the ocular surface detected by microbiome, analysis can activate Toll-Like Receptors (TLR) on resident cells in the cornea, which produce [105], pro- 
inflammatory and chemotactic cytokines resulting in neutrophil recruitment to the corneal stroma and loss of corneal clarity.

$S$. marcescens keratitis isolates were examined in a rabbit model and found to exhibit differences in virulence; further, Hume and Willcox reported that most isolates did not infect $\mathrm{BALB} / \mathrm{c}$ mice $[106,107]$. Zhu et al. showed more recently that $S$. marcescens clinical isolates could infect C57BL/6 mice, although the bacteria were rapidly cleared, and the severity of disease was less than we reported for T3SS expressing $P$. aeruginosa, although it was very similar to T3SS mutants $[108,109]$. However, as in $P$. aeruginosa keratitis, $S$. marcescens corneal infection was dependent on TLR4/MD-2 and IL-1R1 activation of MyD88 [109].

\section{Conclusion: Spectrum of Toll-Like Receptor (TLR)-Associated Corneal Disease Severity}

Studies presented in this review are consistent with the concept that TLR mediated corneal inflammation and bacterial keratitis represent similar host responses that differ primarily in scale, as illustrated in Figure 6. Epithelial exposure to live or killed Gram negative bacteria or to LPS results in TLR4/MD-2 signaling in resident myeloid and corneal epithelial cells to generate pro-inflammatory and chemotactic cytokines in the cornea, which then recruit neutrophils to the corneal stroma. Neutrophils produce reactive oxygen and nitrogen species and matrix metalloproteinases, which have profound antimicrobial activity; however, these agents also have cytotoxic activity for host cells, resulting in tissue damage in the highly organized corneal stroma, and subsequent loss of corneal clarity.

At the lower end of the spectrum of inflammation, corneal inflammation caused by dead bacteria or bacterial products and associated with contact lens wear induce neutrophil containing corneal infiltrates resulting in focal loss of corneal clarity. At the higher end of the spectrum, T3SS expressing $P$. aeruginosa cause severe corneal opacity and ulceration, whereas T3SS mutants are rapidly killed. For Gram-positive bacteria, pneumolysin expressing Streptococcus pneumoniae causes more severe corneal disease than Staphylococcus aureus, especially in developing countries [110]. Although IL-6 was shown to mediate $S$. aureus survival in the cornea, the nature of the host response to both organisms has yet to be fully determined [111,112].

In conclusion, the reports cited in this review contribute to our understanding of the host and bacterial mediators that lead to corneal inflammation and infection, and identify potential targets for immune intervention including TLR blockade, TLR/IL-1R signaling, and neutrophil extravasation. Further, treatment or prevention of corneal disease can be approached by local (topical) rather than systemic application of anti-inflammatory compounds. Current treatment of bacterial keratitis uses antibiotics followed by corticosteroids to reduce the associated inflammation, and steroids are the most common therapeutic approach to treat sterile infiltrates. However, complications associated with long-term steroid use include broad immunosuppression and increased intraocular pressure. To this end, targeting the TLR pathway to inhibit corneal inflammation thus represents a feasible approach for sterile corneal infiltrates and, together with antibiotics, for bacterial keratitis [52, 113, 114].

\section{Acknowledgments}

Some of the studies cited in this review were supported by the National Institutes of Health Grants R01 EY14362 (E.P.), RO1 EY022052 (A.R.) and P30 EY11373 (E.P.). Dr Chinnery and Prof McMenamin are supported by the Australian NH\&MRC. Additional support for this work was provided by the Research to Prevent Blindness Foundation and the Ohio Lions Eye Research Foundation. EP is the recipient of an Alcon Research Institute Award. 


\section{ABBREVIATIONS}

$\begin{array}{ll}\text { ADPRT } & \text { ADP ribosyltransferase } \\ \text { AMP } & \text { antimicrobial peptide } \\ \text { GAP } & \text { GTPase activating protein } \\ \text { HCEC } & \text { Human corneal epithelial cells } \\ \text { HSV } & \text { Herpes simplex virus } \\ \text { IRAK } & \text { IL-1 Receptor Associated Kinase } \\ \text { IRF } & \text { Interferon Regulatory Factor } \\ \text { ITAM } & \text { Immunoreceptor tyrosine-based activation motif } \\ \text { MD-2 } & \text { myeloid differentiation factor-2 } \\ \text { MMP } & \text { matrix metalloproteinase } \\ \text { NLRC4 } & \text { Nod Like Receptor family CARD Domain-containing protein } \\ \text { PLC } \boldsymbol{\gamma} \text { 2 } & \text { Phosphoinositide phospholipase C } \\ \text { ROS } & \text { reactive oxygen species } \\ \text { STAT } & \text { Signal Transducers and Activators of Transcription } \\ \text { Syk } & \text { Spleen tyrosine kinase } \\ \text { TIR } & \text { Toll/IL-1R intracellular domain } \\ \text { TLR } & \text { Toll-Like Receptor } \\ \text { TRAF } & \text { TNF-Receptor Associated Factor } \\ \text { TRIF } & \text { TIR domain-containing adaptor inducing IFN- } \beta \\ \text { TIRAP } & \text { TIR-domain-containing adaptor protein } \\ \text { T3SS } & \text { Type III secretion system } \\ \end{array}$

\section{REFERENCES}

[1]. www.who.int/blindness/Vision2020 report.pdf

[2]. Saint Andre A, Blackwell NM, Hall LR, et al. The role of endosymbiotic Wolbachia bacteria in the pathogenesis of river blindness. Science. 2002; 295:1892-1895. [PubMed: 11884755]

[3]. Turner JD, Langley RS, Johnston KL, et al. Wolbachia lipoprotein stimulates innate and adaptive immunity through Toll-like receptors 2 and 6 to induce disease manifestations of filariasis. J Biol Chem. 2009; 284:22364-22378. [PubMed: 19458089]

[4]. Tamarozzi F, Halliday A, Gentil K, et al. Onchocerciasis: the role of Wolbachia bacterial endosymbionts in parasite biology, disease pathogenesis, and treatment. Clin Microbiol Rev. 2011; 24:459-468. [PubMed: 21734243]

[5]. Knickelbein JE, Khanna KM, Yee MB, et al. Noncytotoxic lytic granule-mediated CD8 T cell inhibition of HSV-1 reactivation from neuronal latency. Science. 2008; 322:268-271. [PubMed: 18845757]

[6]. Gimenez F, Suryawanshi A, Rouse BT. Pathogenesis of herpes stromal keratitis-a focus on corneal neovascularization. Prog Retin Eye Res. 2012 [Epub ahead of print].

[7]. Suryawanshi A, Mulik S, Sharma S, et al. Ocular neovascularization caused by herpes simplex virus type 1 infection results from breakdown of binding between vascular endothelial growth factor A and its soluble receptor. J Immunol. 2011; 186:3653-3665. [PubMed: 21325621] 
[8]. Karthikeyan RS, Leal SM Jr. Prajna NV, et al. Expression of innate and adaptive immune mediators in human corneal tissue infected with Aspergillus or fusarium. J Infect Dis. 2011; 204:942-950. [PubMed: 21828275]

[9]. Leal SM Jr. Cowden S, Hsia YC, et al. Distinct roles for Dectin-1 and TLR4 in the pathogenesis of Aspergillus fumigatus keratitis. PLoS Pathog. 2010; 6:e1000976. [PubMed: 20617171]

[10]. Clarke DW, Niederkorn JY. The immunobiology of Acanthamoeba keratitis. Microbes Infect. 2006; 8:1400-1405. [PubMed: 16697233]

[11]. Iovieno A, Ledee DR, Miller D, Alfonso EC. Detection of bacterial endosymbionts in clinical Acanthamoeba isolates. Ophthalmology. 2010; 117:445-452. [PubMed: 20031220]

[12]. Bhosai SJ, Bailey RL, Gaynor BD, Lietman TM. Trachoma: an update on prevention, diagnosis, and treatment. Curr Opin Ophthalmol. 2012; 23:288-295. [PubMed: 22569465]

[13]. Leal SM Jr. Pearlman E. The role of cytokines and pathogen recognition molecules in fungal keratitis_insights from human disease and animal models. Cytokine. 2012; 58:107-111. [PubMed: 22280957]

[14]. Hazlett LD. Corneal response to Pseudomonas aeruginosa infection. Prog Retin Eye Res. 2004; 23:1-30. [PubMed: 14766315]

[15]. Hazlett LD. Inflammatory response to Pseudomonas aeruginosa keratitis. Ocul Surf. 2005; 3:S139-S141. [PubMed: 17216103]

[16]. Hazlett LD, Hendricks RL. Reviews for immune privilege in the year 2010: immune privilege and infection. Ocul Immunol Inflamm. 2010; 18:237-243. [PubMed: 20662654]

[17]. Garreis F, Gottschalt M, Paulsen FP. Antimicrobial peptides as a major part of the innate immune defense at the ocular surface. Dev Ophthalmol. 2012; 45:16-22. [PubMed: 20502023]

[18]. Dartt DA. Tear lipocalin: structure and function. Ocul Surf. 2011; 9:126-138. [PubMed: 21791187]

[19]. Flanagan JL, Willcox MD. Role of lactoferrin in the tear film. Biochimie. 2009; 91:35-43. [PubMed: 18718499]

[20]. Govindarajan B, Gipson IK. Membrane-tethered mucins have multiple functions on the ocular surface. Exp Eye Res. 2011; 90:655-663. [PubMed: 20223235]

[21]. McDermott AM. The role of antimicrobial peptides at the ocular surface. Ophthalmic Res. 2009; 41:60-75. [PubMed: 19122467]

[22]. Augustin DK, Heimer SR, Tam C, et al. Role of defensins in corneal epithelial barrier function against Pseudomonas aeruginosa traversal. Infect Immun. 2011; 79:595-605. [PubMed: 21115716]

[23]. Wu M, McClellan SA, Barrett RP, et al. Beta-defensins 2 and 3 together promote resistance to Pseudomonas aeruginosa keratitis. J Immunol. 2009; 183:8054-8060. [PubMed: 19933858]

[24]. Tam C, Mun JJ, Evans DJ, Fleiszig SM. Cytokeratins mediate epithelial innate defense through their antimicrobial properties. J Clin Invest. 2012; 122:3665-3677. [PubMed: 23006328]

[25]. Pearlman E, Johnson A, Adhikary G, et al. Toll-like receptors at the ocular surface. Ocul Surf. 2008; 6:108-116. [PubMed: 18781257]

[26]. Kawai T, Akira S. The role of pattern-recognition receptors in innate immunity: update on Tolllike receptors. Nat Immunol. 2011; 11:373-384. [PubMed: 20404851]

[27]. Zanoni I, Ostuni R, Marek LR, et al. CD14 controls the LPS-induced endocytosis of Toll-like receptor 4. Cell. 2011; 147:868-880. [PubMed: 22078883]

[28]. Yarovinsky F, Zhang D, Andersen JF, et al. TLR11 activation of dendritic cells by a protozoan profilin-like protein. Science. 2005; 308:1626-1629. [PubMed: 15860593]

[29]. Zhang D, Zhang G, Hayden MS, et al. A toll-like receptor that prevents infection by uropathogenic bacteria. Science. 2004; 303:1522-1526. [PubMed: 15001781]

[30]. Shimazu R, Akashi S, Ogata H, et al. MD-2, a molecule that confers lipopolysaccharide responsiveness on Toll-like receptor 4. J Exp Med. 1999; 189:1777-1782. [PubMed: 10359581]

[31]. Viriyakosol S, Tobias PS, Kitchens RL, Kirkland TN. MD-2 binds to bacterial lipopolysaccharide. J Biol Chem. 2001; 276:38044-38051. [PubMed: 11500507] 
[32]. Visintin A, Mazzoni A, Spitzer JA, Segal DM. Secreted MD-2 is a large polymeric protein that efficiently confers lipopolysaccharide sensitivity to Toll-like receptor 4. Proc Natl Acad Sci USA. 2001; 98:12156-12161. [PubMed: 11593030]

[33]. Park BS, Song DH, Kim HM, et al. The structural basis of lipopolysaccharide recognition by the TLR4-MD-2 complex. Nature. 2009; 458:1191-1195. [PubMed: 19252480]

[34]. Gioannini TL, Teghanemt A, Zhang D, et al. Isolation of an endotoxin-MD-2 complex that produces Toll-like receptor 4-dependent cell activation at picomolar concentrations. Proc Natl Acad Sci USA. 2004; 101:4186-4191. [PubMed: 15010525]

[35]. Brissette-Storkus CS, Reynolds SM, Lepisto AJ, Hendricks RL. Identification of a novel macrophage population in the normal mouse corneal stroma. Invest Ophthalmol Vis Sci. 2002; 43:2264-2271. [PubMed: 12091426]

[36]. Chinnery HR, Pearlman E, McMenamin PG. Cutting edge: membrane nanotubes in vivo: a feature of MHC class II+ cells in the mouse cornea. J Immunol. 2008; 180:5779-5783. [PubMed: 18424694]

[37]. Chinnery HR, Ruitenberg MJ, Plant GW, et al. The chemokine receptor CX3CR1 mediates homing of MHC class II-positive cells to the normal mouse corneal epithelium. Invest Ophthalmol Vis Sci. 2007; 48:1568-1574. [PubMed: 17389486]

[38]. Hamrah P, Dana MR. Corneal antigen-presenting cells. Chem Immunol Allergy. 2007; 92:58-70. [PubMed: 17264483]

[39]. Hamrah P, Huq SO, Liu Y, et al. Corneal immunity is mediated by heterogeneous population of antigen-presenting cells. J Leukoc Biol. 2003; 74:172-178. [PubMed: 12885933]

[40]. Sun Y, Karmakar M, Roy S, et al. TLR4 and TLR5 on corneal macrophages regulate Pseudomonas aeruginosa keratitis by signaling through MyD88-dependent and -independent pathways. J Immunol. 2010; 185:4272-4283. [PubMed: 20826748]

[41]. Huang X, Du W, McClellan SA, et al. TLR4 is required for host resistance in Pseudomonas aeruginosa keratitis. Invest Ophthalmol Vis Sci. 2006; 47:4910-4916. [PubMed: 17065506]

[42]. McClellan SA, Huang X, Barrett RP, et al. Macrophages restrict Pseudomonas aeruginosa growth, regulate polymorphonuclear neutrophil influx, and balance pro- and anti-inflammatory cytokines in BALB/c mice. J Immunol. 2003; 170:5219-5227. [PubMed: 12734370]

[43]. Leal SM Jr. Vareechon C, Cowden S, et al. Fungal antioxidant pathways promote survival against neutrophils during infection. J Clin Invest. 2012; 122:2482-2498. [PubMed: 22706306]

[44]. Nathan C. Neutrophils and immunity: challenges and opportunities. Nat Rev Immunol. 2006; 6:173-182. [PubMed: 16498448]

[45]. Tam C, Mun JJ, Evans DJ, Fleiszig SM. The impact of inoculation parameters on the pathogenesis of contact lens-related infectious keratitis. Invest Ophthalmol Vis Sci. 2010; 51:3100-3106. [PubMed: 20130275]

[46]. Adhikary G, Sun Y, Pearlman E. C-Jun NH2 terminal kinase (JNK) is an essential mediator of Toll-like receptor 2-induced corneal inflammation. J Leukoc Biol. 2008; 83:991-997. [PubMed: 18218857]

[47]. Kumar A, Zhang J, Yu FS. Toll-like receptor 2-mediated expression of beta-defensin-2 in human corneal epithelial cells. Microbes Infect. 2006; 8:380-389. [PubMed: 16242370]

[48]. Johnson AC, Li X, Pearlman E. MyD88 functions as a negative regulator of TLR3/TRIF-induced corneal inflammation by inhibiting activation of c-Jun N-terminal kinase. J Biol Chem. 2008; 283:3988-3996. [PubMed: 18057004]

[49]. Ueta M, Hamuro J, Kiyono H, Kinoshita S. Triggering of TLR3 by polyI:C in human corneal epithelial cells to induce inflammatory cytokines. Biochem Biophys Res Commun. 2005; 331:285-294. [PubMed: 15845391]

[50]. Zhang J, Xu K, Ambati B, Yu FS. Toll-like receptor 5-mediated corneal epithelial inflammatory responses to Pseudomonas aeruginosa flagellin. Invest Ophthalmol Vis Sci. 2003; 44:4247-4254. [PubMed: 14507868]

[51]. Chinnery HR, McLenachan S, Binz N, et al. TLR9 ligand CpG-ODN applied to the injured mouse cornea elicits retinal inflammation. Am J Pathol. 2012; 180:209-220. [PubMed: 22085974] 
[52]. Sun Y, Pearlman E. Inhibition of corneal inflammation by the TLR4 antagonist Eritoran tetrasodium (E5564). Invest Ophthalmol Vis Sci. 2009; 50:1247-1254. [PubMed: 18936141]

[53]. Ueta M, Nochi T, Jang MH, et al. Intracellularly expressed TLR2s and TLR4s contribution to an immunosilent environment at the ocular mucosal epithelium. J Immunol. 2004; 173:3337-3347. [PubMed: 15322197]

[54]. Visintin A, Halmen KA, Khan N, et al. MD-2 expression is not required for cell surface targeting of Toll-like receptor 4 (TLR4). J Leukoc Biol. 2006; 80:1584-1592. [PubMed: 16946018]

[55]. Zhang J, Kumar A, Wheater M, Yu FS. Lack of MD-2 expression in human corneal epithelial cells is an underlying mechanism of lipopolysaccharide (LPS) unresponsiveness. Immunol Cell Biol. 2009; 87:141-148. [PubMed: 18936773]

[56]. Roy S, Sun Y, Pearlman E. Interferon-gamma-induced MD-2 protein expression and lipopolysaccharide (LPS) responsiveness in corneal epithelial cells is mediated by Janus tyrosine kinase-2 activation and direct binding of STAT1 protein to the MD-2 promoter. J Biol Chem. 2011; 286:23753-23762. [PubMed: 21572044]

[57]. Hazlett LD, Li Q, Liu J, et al. NKT cells are critical to initiate an inflammatory response after Pseudomonas aeruginosa ocular infection in susceptible mice. J Immunol. 2007; 179:1138-1146. [PubMed: 17617607]

[58]. Kumar A, Yin J, Zhang J, Yu FS. Modulation of corneal epithelial innate immune response to pseudomonas infection by flagellin pretreatment. Invest Ophthalmol Vis Sci. 2007; 48:46644670. [PubMed: 17898290]

[59]. Redfern RL, Reins RY, McDermott AM. Toll-like receptor activation modulates antimicrobial peptide expression by ocular surface cells. Exp Eye Res. 2011; 92:209-220. [PubMed: 21195713]

[60]. Rudner XL, Kernacki KA, Barrett RP, Hazlett LD. Prolonged elevation of IL-1 in Pseudomonas aeruginosa ocular infection regulates macrophage-inflammatory protein-2 production, polymorphonuclear neutrophil persistence, and corneal perforation. J Immunol. 2000; 164:65766582. [PubMed: 10843717]

[61]. Karmakar M. Cutting Edge: IL-1 $\beta$ processing during Pseudomonas aeruginosa infection is mediated by neutrophil serine proteases and is independent of NLRC4 and Caspase-1. Cutting Edge J Immunol. 2012; 189(9):4231-4235.

[62]. Gross O, Thomas CJ, Guarda G, Tschopp J. The inflammasome: an integrated view. Immunol Rev. 2011; 243:136-151. [PubMed: 21884173]

[63]. Schroder K, Tschopp J. The inflammasomes. Cell. 2010; 140:821-832. [PubMed: 20303873]

[64]. Miao EA, Alpuche-Aranda CM, Dors M, et al. Cytoplasmic flagellin activates caspase-1 and secretion of interleukin 1beta via Ipaf. Nat Immunol. 2006; 7:569-575. [PubMed: 16648853]

[65]. Miao EA, Ernst RK, Dors M, et al. Pseudomonas aeruginosa activates caspase 1 through Ipaf. Proc Natl Acad Sci USA. 2008; 105:2562-2567. [PubMed: 18256184]

[66]. Miao EA, Mao DP, Yudkovsky N, et al. Innate immune detection of the type III secretion apparatus through the NLRC4 inflammasome. Proc Natl Acad Sci USA. 2010; 107:3076-3080. [PubMed: 20133635]

[67]. Tomalka J, Ganesan S, Azodi E, et al. A novel role for the NLRC4 inflammasome in mucosal defenses against the fungal pathogen Candida albicans. PLoS Pathog. 2011; 7:e1002379. [PubMed: 22174673]

[68]. Franchi L, Stoolman J, Kanneganti TD, et al. Critical role for Ipaf in Pseudomonas aeruginosainduced caspase-1 activation. Eur J Immunol. 2007; 37:3030-3039. [PubMed: 17935074]

[69]. Black RA, Kronheim SR, Cantrell M, et al. Generation of biologically active interleukin-1 beta by proteolytic cleavage of the inactive precursor. J Biol Chem. 1988; 263:9437-9442. [PubMed: 3288634]

[70]. Hazuda DJ, Strickler J, Kueppers F, et al. Processing of precursor interleukin 1 beta and inflammatory disease. J Biol Chem. 1990; 265:6318-6322. [PubMed: 2156847]

[71]. Mankan AK, Dau T, Jenne D, Hornung V. The NLRP3/ASC/Caspase-1 axis regulates IL-1beta processing in neutrophils. Eur J Immunol. 2011; 42(3):710-715. [PubMed: 22213227] 
[72]. Thakur A, Barrett RP, Hobden JA, Hazlett LD. Caspase-1 inhibitor reduces severity of Pseudomonas aeruginosa keratitis in mice. Invest Ophthalmol Vis Sci. 2004; 45:3177-3184. [PubMed: 15326138]

[73]. Thakur A, Barrett RP, McClellan S, Hazlett LD. Regulation of Pseudomonasaeruginosa corneal infection in IL-1 beta converting enzyme (ICE, caspase-1) deficient mice. Curr Eye Res. 2004; 29:225-233. [PubMed: 15590467]

[74]. Wald D, Qin J, Zhao Z, et al. SIGIRR, a negative regulator of Toll-like receptor-interleukin 1 receptor signaling. Nat Immunol. 2003; 4:920-927. [PubMed: 12925853]

[75]. Huang X, Hazlett LD, Du W, Barrett RP. SIGIRR promotes resistance against Pseudomonas aeruginosa keratitis by down-regulating type-1 immunity and IL-1R1 and TLR4 signaling. J Immunol. 2006; 177:548-556. [PubMed: 16785552]

[76]. Huang X, Du W, Barrett RP, Hazlett LD. ST2 is essential for Th2 responsiveness and resistance to Pseudomonas aeruginosa keratitis. Invest Ophthalmol Vis Sci. 2007; 48:4626-4633. [PubMed: 17898286]

[77]. Jiang X, McClellan SA, Barrett RP, et al. VIP and growth factors in the infected cornea. Invest Ophthalmol Vis Sci. 2011; 52:6154-6161. [PubMed: 21666233]

[78]. Jiang X, McClellan SA, Barrett RP, et al. Vasoactive intestinal peptide downregulates proinflammatory TLRs while upregulating anti-inflammatory TLRs in the infected cornea. J Immunol. 2012; 189:269-278. [PubMed: 22661083]

[79]. Hazlett LD, McClellan SA, Barrett RP, et al. Spantide I decreases type I cytokines, enhances IL-10, and reduces corneal perforation in susceptible mice after Pseudomonasaeruginosa infection. Invest Ophthalmol Vis Sci. 2007; 48:797-807. [PubMed: 17251480]

[80]. Zhou Z, Barrett RP, McClellan SA, et al. Substance P delays apoptosis, enhancing keratitis after Pseudomonas aeruginosa infection. Invest Ophthalmol Vis Sci. 2008; 49:4458-4467. [PubMed: 18566468]

[81]. Burdelya LG, Krivokrysenko, Tallant TC, et al. An agonist of toll-like receptor 5 has radioprotective activity in mouse and primate models. Science. 2008; 320:226-230. [PubMed: 18403709]

[82]. Vijay-Kumar M, Aitken JD, Sanders CJ, et al. Flagellin treatment protects against chemicals, bacteria, viruses, and radiation. J Immunol. 2008; 180:8280-8285. [PubMed: 18523294]

[83]. Kumar A, Gao N, Standiford TJ, et al. Topical flagellin protects the injured corneas from Pseudomonas aeruginosa infection. Microbes Infect. 2010; 12:978-989. [PubMed: 20601077]

[84]. Kumar A, Hazlett LD, Yu FS. Flagellin suppresses the inflammatory response and enhances bacterial clearance in a murine model of Pseudomonas aeruginosa keratitis. Infect Immun. 2008; 76:89-96. [PubMed: 17938214]

[85]. Yu FS, Cornicelli MD, Kovach MA, et al. Flagellin stimulates protective lung mucosal immunity: role of cathelicidin-related antimicrobial peptide. J Immunol. 2011; 185:1142-1149. [PubMed: 20566829]

[86]. Galan JE, Wolf-Watz H. Protein delivery into eukaryotic cells by type III secretion machines. Nature. 2006; 444:567-573. [PubMed: 17136086]

[87]. Hauser AR. The type III secretion system of Pseudomonas aeruginosa: infection by injection. Nat Rev Microbiol. 2009; 7:654-665. [PubMed: 19680249]

[88]. Sato H, Frank DW. ExoU is a potent intracellular phospholipase. Mol Microbiol. 2004; 53:12791290. [PubMed: 15387809]

[89]. Barbieri JT, Sun J. Pseudomonas aeruginosa ExoS and ExoT. Rev Physiol Biochem Pharmacol. 2004; 152:79-92. [PubMed: 15375697]

[90]. Kazmierczak BI, Mostov K, Engel JN. Epithelial cell polarity alters Rho-GTPase responses to Pseudomonas aeruginosa. Mol Biol Cell. 2004; 15:411-419. [PubMed: 14595106]

[91]. Krall R, Sun J, Pederson KJ, Barbieri JT. In vivo rho GTPase-activating protein activity of Pseudomonas aeruginosa cytotoxin ExoS. Infect Immun. 2002; 70:360-367. [PubMed: 11748202]

[92]. Engel J, Balachandran P. Role of Pseudomonas aeruginosa type III effectors in disease. Curr Opin Microbiol. 2009; 12:61-66. [PubMed: 19168385] 
[93]. Feltman H, Schulert G, Khan S, et al. Prevalence of type III secretion genes in clinical and environmental isolates of Pseudomonas aeruginosa. Microbiology. 2001; 147:2659-2669. [PubMed: 11577145]

[94]. Cowell BA, Weissman BA, Yeung KK, et al. Phenotype of Pseudomonas aeruginosa isolates causing corneal infection between 1997 and 2000. Cornea. 2003; 22:131-134. [PubMed: 12605047]

[95]. Lee EJ, Cowell BA, Evans DJ, Fleiszig SM, et al. Contribution of ExsA-regulated factors to corneal infection by cytotoxic and invasive Pseudomonas aeruginosa in a murine scarification model. Invest Ophthalmol Vis Sci. 2003; 44:3892-3898. [PubMed: 12939306]

[96]. Stover CK, Pham XQ, Erwin AL, et al. Complete genome sequence of Pseudomonas aeruginosa PAO1, an opportunistic pathogen. Nature. 2000; 406:959-964. [PubMed: 10984043]

[97]. Angus AA, Lee AA, Augustin DK, et al. Pseudomonas aeruginosa induces membrane blebs in epithelial cells, which are utilized as a niche for intracellular replication and motility. Infect Immun. 2008; 76:1992-2001. [PubMed: 18316391]

[98]. Angus AA, Evans DJ, Barbieri JT, Fleiszig SM. The ADP-ribosylation domain of Pseudomonas aeruginosa ExoS is required for membrane Bleb-Niche formation and bacterial survival within epithelial cells. Infect Immun. 2010; 78(11):4500-4510. [PubMed: 20732998]

[99]. Behlau I, Gilmore MS. Microbial biofilms in ophthalmology and infectious disease. Arch Ophthalmol. 2008; 126:1572-1581. [PubMed: 19001227]

[100]. Mukherjee PK, Zhou G, Munyon R, Ghannoum MA. Candida biofilm: a well-designed protected environment. Med Mycol. 2005; 43:191-208. [PubMed: 16010846]

[101]. Szczotka-Flynn LB, Imamura Y, Chandra J, et al. Increased resistance of contact lens-related bacterial biofilms to antimicrobial activity of soft contact lens care solutions. Cornea. 2009; 28:918-926. [PubMed: 19654521]

[102]. Szczotka-Flynn LB, Pearlman E, Ghannoum M. Microbial contamination of contact lenses, lens care solutions, and their accessories: a literature review. Eye Contact Lens. 2010; 36:116-129. [PubMed: 20168237]

[103]. Johnson AC, Heinzel FP, Diaconu E, et al. Activation of toll-like receptor (TLR)2, TLR4, and TLR9 in the mammalian cornea induces MyD88-dependent corneal inflammation. Invest Ophthalmol Vis Sci. 2005; 46:589-595. [PubMed: 15671286]

[104]. Szczotka-Flynn L, Diaz M. Risk of corneal inflammatory events with silicone hydrogel and low dk hydrogel extended contact lens wear: a meta-analysis. Optom Vis Sci. 2007; 84:247-256. [PubMed: 17435508]

[105]. Dong Q, Brulc JM, Iovieno A, et al. Diversity of bacteria at healthy human conjunctiva. Invest Ophthalmol Vis Sci. 2011; 52:5408-5413. [PubMed: 21571682]

[106]. Hume EB, Conerly LL, Moreau JM, et al. Serratia marcescens keratitis: strain-specific corneal pathogenesis in rabbits. Curr Eye Res. 1999; 19:525-532. [PubMed: 10550795]

[107]. Willcox MD, Hume EB. Differences in the pathogenesis of bacteria isolated from contact-lensinduced infiltrative conditions. Aust N Z J Ophthalmol. 1999; 27:231-233. [PubMed: 10484200]

[108]. Sun Y, Karmakar M, Taylor PR, et al. ExoS and ExoT ADP ribosyltransferase activities mediate Pseudomonas aeruginosa keratitis by promoting neutrophil apoptosis and bacterial survival. J Immunol. 2012; 188:1884-1895. [PubMed: 22250085]

[109]. Zhou R, Zhang R, Sun Y, et al. Innate immune regulation of Serratia marcescens induced corneal inflammation and infection. Invest Ophthalmol Vis Sci. 2012; 53(11):7382-7388. [PubMed: 23033384]

[110]. Bharathi MJ, Ramakrishnan R, Meenakshi R, et al. Microbial keratitis in South India: influence of risk factors, climate, and geographical variation. Ophthalmic Epidemiol. 2007; 14:61-69. [PubMed: 17464852]

[111]. Hume EB, Cole N, Garthwaite LL, et al. A protective role for IL-6 in staphylococcal microbial keratitis. Invest Ophthalmol Vis Sci. 2006; 47:4926-4930. [PubMed: 17065508]

[112]. Moore QC 3rd, McCormick CC, Norcross EW, et al. Development of a Streptococcus pneumoniae keratitis model in mice. Ophthalmic Res. 2009; 42:141-146. [PubMed: 19628954]

[113]. Sun Y, Fox T, Adhikary G, et al. Inhibition of corneal inflammation by liposomal delivery of short-chain, C-6 ceramide. J Leukoc Biol. 2008; 83:1512-1521. [PubMed: 18372342] 
[114]. Sun Y, Zhang R, Gadek TR, et al. Corneal inflammation is inhibited by the LFA-1 antagonist, lifitegrast (SAR 1118). J Ocul Pharmacol Ther. 2013; 29 In press. 

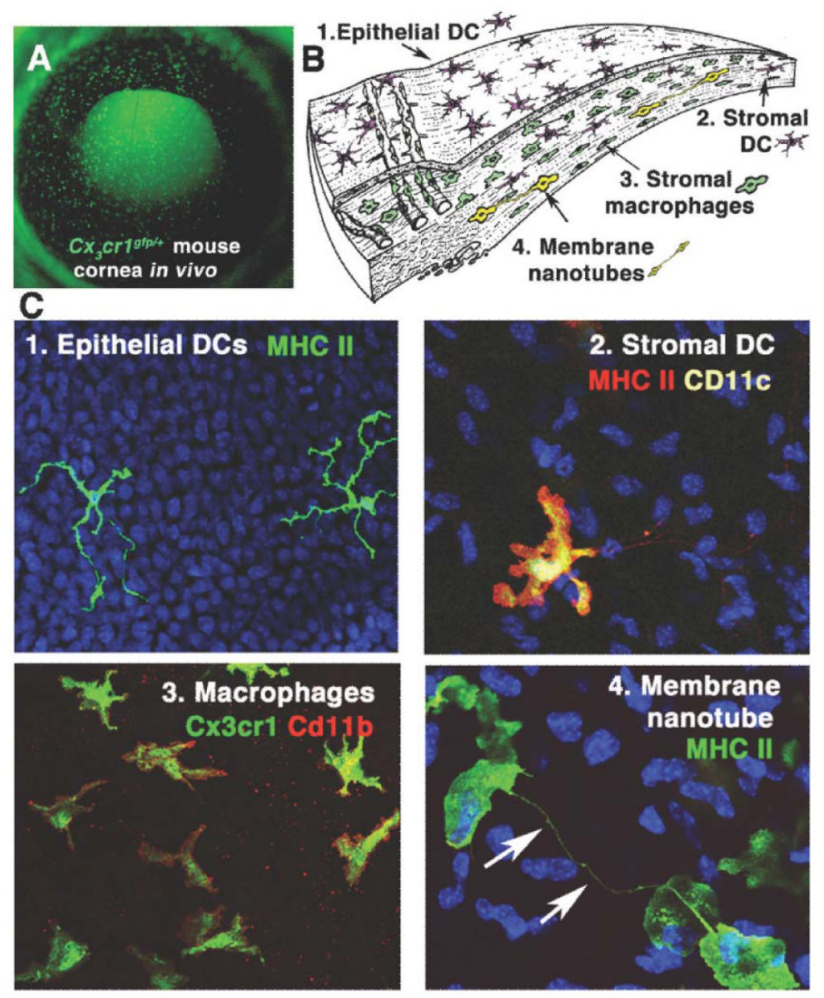

FIGURE 1. Resident myeloid cells in the cornea

A,B: $\mathrm{CX}_{3} \mathrm{CR} 1^{\mathrm{GFP}+}$ cells in a normal mouse cornea (A, original magnification is $\mathrm{x} 20$ ), and the distribution of epithelial and stromal dendritic cells (DC) and stromal macrophages (B). C: Mouse corneal whole mounts from wild type (panel 1, 4), CD11c eYFP (panel 3) or $\mathrm{CX}_{3} \mathrm{CR} 1^{\mathrm{GFP}+}$ mice were incubated with antibodies to MHC class II or CD11b, counterstained with DAPI, and visualized by confocal microscopy. Images of each cell population illustrated in Figure 1B is shown in panels 1-4, including in vivo MHC II membrane nanotubes (panel 4), which were present in the cornea $24 \mathrm{~h}$ after topical exposure to+LPS. Original magnification is $\mathrm{x} 400$, and similar images and detailed descriptions are in references $[35,39,40]$. 


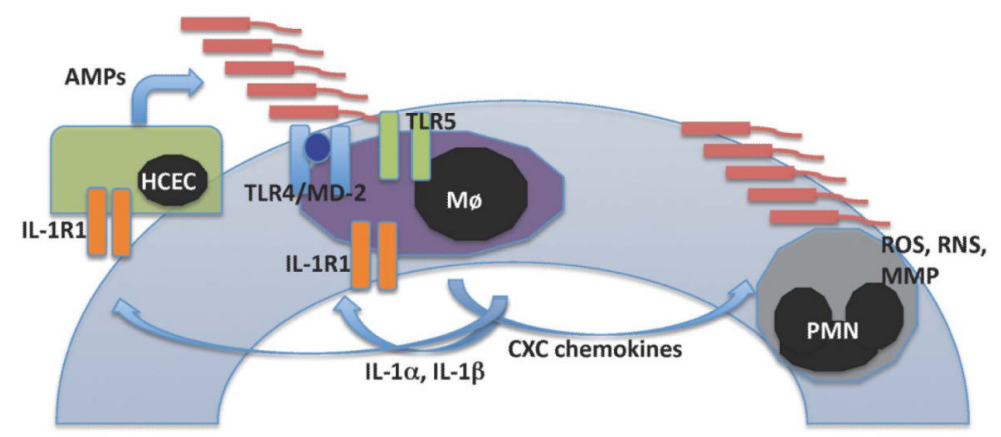

FIGURE 2. Predicted sequence of events in $P$. aeruginosa keratitis

Following corneal abrasion and infection, TLR4/MD-2 and TLR5 are activated on resident macrophages leading to production of CXC chemokines and pro-inflammatory cytokines by resident macrophages (Mø) including IL-1 $a$ and IL-1 $\beta$. These cytokines mediate neutrophil (PMN) recruitment from peripheral capillaries in the cornea, which secrete reactive oxygen and nitrogen species (ROS, RNS) and matrix metalloproteinases (MMP) that disrupt the normal architecture of the corneal stroma and results in loss of corneal clarity. IL-1 $a$ and IL- $1 \beta$ have autocrine and paracrine effects on cells expressing IL-1R1, including corneal epithelial cells (HCEC), resulting in production of chemokines and antimicrobial peptides (AMP), which exacerbate the inflammatory response. The diagram is based primarily from data in reference [40]. 


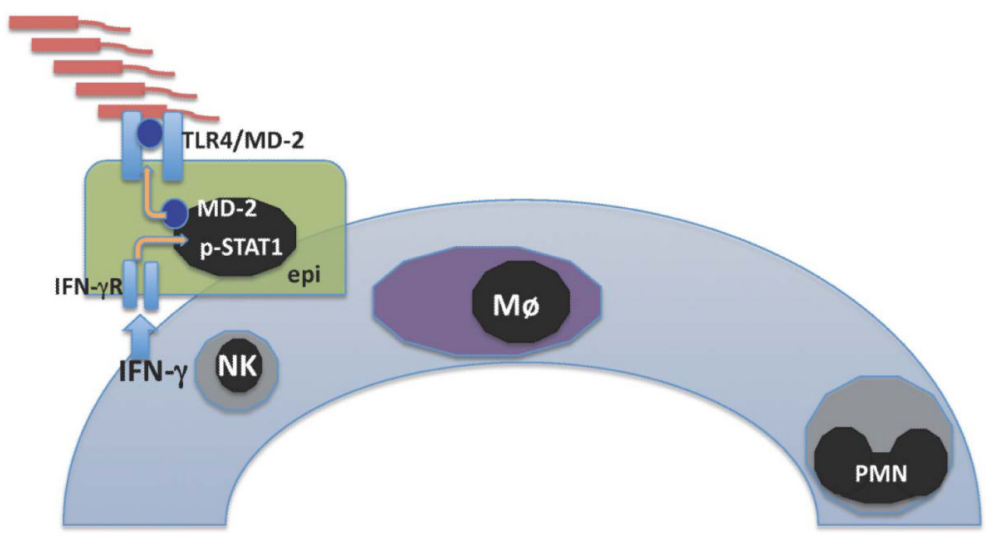

FIGURE 3. LPS responsiveness in human corneal epithelial (HCE) cells

Following infection with $\boldsymbol{P}$. aeruginosa, natural killer (NK) cells are recruited to the corneal stroma, and produce IFN- $\gamma$. IFN- $\gamma$ receptor activation on corneal epithelial cells (epi) leads through $p$-STAT1 to MD-2 transcription and translocation to the cell surface with constitutively expressed TLR4. Corneal epithelial cells can then respond to LPS by producing chemotactic and pro-inflammatory cytokines in addition to AMPs. The diagram is based primarily on data presented in reference [56]. 


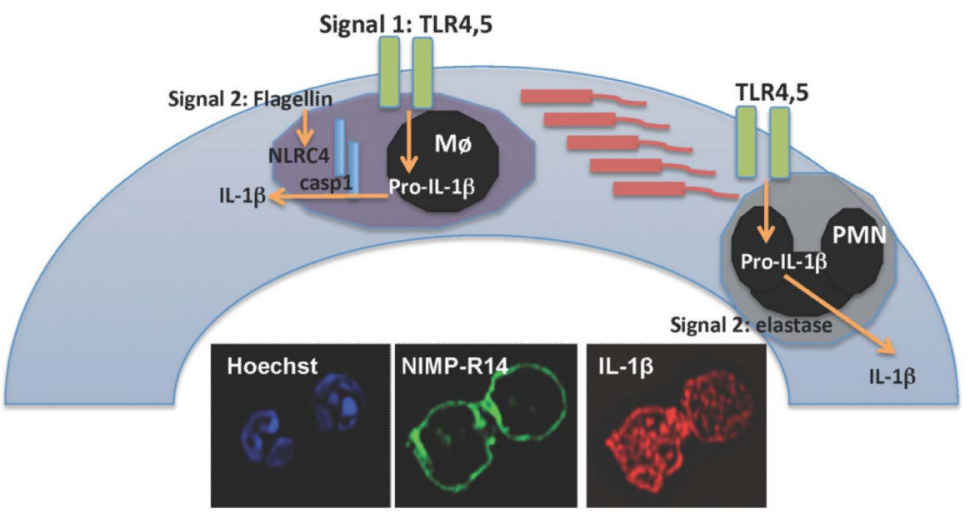

FIGURE 4. Neutrophil mediated IL-1 $\beta$ production and processing in $P$. aeruginosa keratitis In macrophages (Mø), production of the mature, active form of IL-1 $\beta$ is a two-step process involving TLR mediated transcription of the pro-form, followed by caspase- 1 cleavage to the mature cytokine that is secreted. This second step is mediated by the NLRC4/Ipaf inflammasome, which recognizes intracellular flagellin. During acute infection, neutrophils (PMN) are the primary source of IL-1 $\beta$, and the mature form is cleaved by serine proteases, including elastase that is in primary granules. The diagram is based primarily on data presented in reference [61]. Confocal microscopy shows neutrophils from $P$. aeruginosa infected corneas after immunostaining for surface NIMP-R14 and intracellular IL-1 $\beta$. Nuclear morphology is shown by Hoescht staining. Images were reproduced with permission from the Journal of Immunology. 


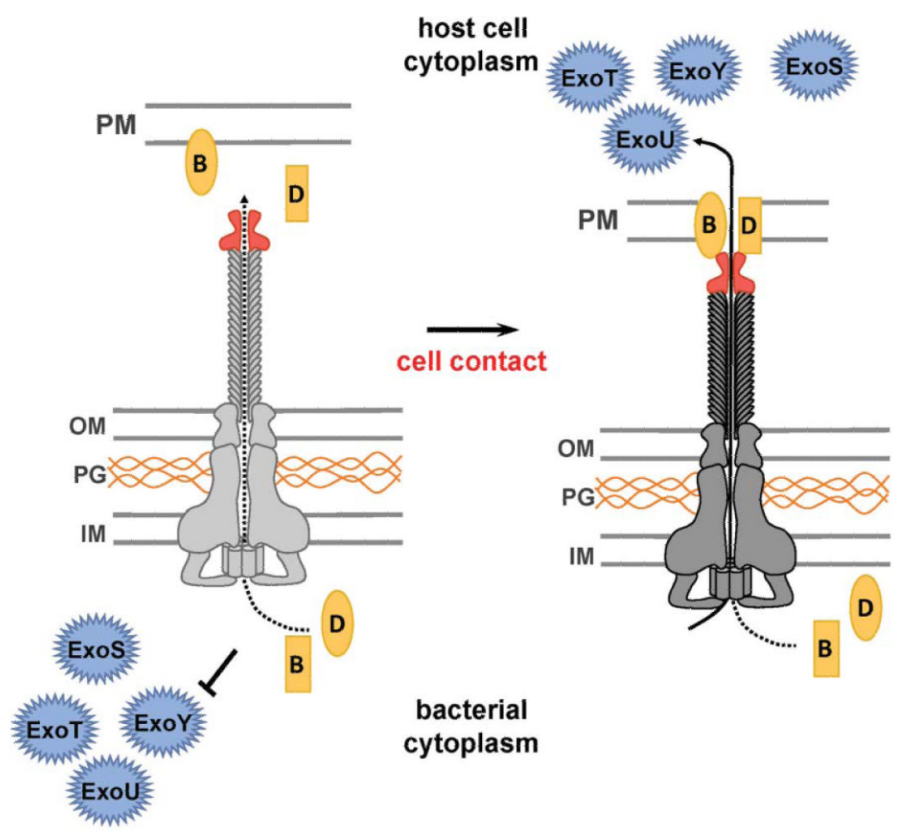

FIGURE 5. The type III secretion system (T3SS)

The T3SS is preassembled and spans the bacterial cell envelope (IM, inner membrane, OM, outer membrane and PG, peptidoglycan layer). Upon cell contact, the pore-forming translocator proteins, PopB (B) and PopD (D), assemble into a pore, which docks to the needle tip (PcrV, red). Subsequent to assembly of the translocation pore, effector secretion is triggered, resulting in export of effector proteins across the bacterial cell envelope and host cell plasma membrane (PM) into the cytosol of the targeted cell. To date, four effector proteins have been described in $P$. aeruginosa, ExoS, ExoT, ExoY, and ExoU, although the exact complement of effectors varies among strains. Recent studies demonstrated that the ADP ribosyltransferase activities of ExoS and ExoT mediate bacterial survival in the cornea by promoting neutrophil apoptosis [96]. The ADPR activity of ExoS also mediates sequestration of $P$. aeruginosa in membrane blebs in corneal epithelial cells $[97,98]$. 


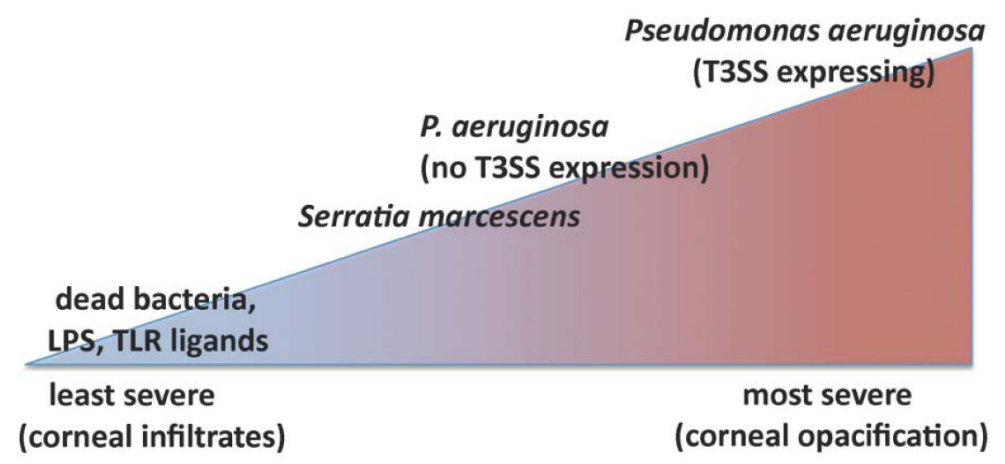

FIGURE 6. Spectrum of Toll-Like Receptor (TLR)-associated corneal disease severity TLR mediated inflammation occurs with live or dead bacteria or bacterial products that activate TLRs. Whereas TLR stimulation of abraded corneas induces mild corneal inflammation similar to contact lens associated corneal infiltrates, infection with T3SS expressing $P$. aeruginosa causes severe corneal opacification and ulceration. Intermediate disease severity is detected following infection with $P$. aeruginosa T3SS mutants and with Serratia marcescens; however, TLR activation is detected in each situation, indicating that TLRs are a feasible target for therapeutic intervention. Diagram is based primarily on data from references [52, 108, 109]. 